\title{
The Ankle-Link Antigen: an Epitope Sensitive to Calcium Chelation Associated with the Hair-Cell Surface and the Calycal Processes of Photoreceptors
}

\author{
Richard Goodyear and Guy Richardson \\ School of Biological Sciences, The University of Sussex, Falmer, Brighton, BN1 9QG, United Kingdom
}

A monoclonal antibody, $\mathrm{mAb} E 40$, that specifically recognizes hair cells and photoreceptors was derived from a mouse immunized with a membrane fraction prepared from the sensory maculae of the chick inner ear. In the mature chick inner ear, punctate labeling is observed along each stereocilium, but staining is mostly concentrated around the basal end of the sensory hair bundles, where it is closely associated with surface specializations known as ankle links. The epitope recognized by $m A b$ E40 is therefore referred to as the ankle-link antigen (ALA). During early embryogenesis, the ALA is initially distributed evenly over the surface of the hair bundle. As development proceeds, it becomes more restricted to the base of the hair bundle, although a spot of the ALA remains associated with the bundle tip until just before hatching. In the eye, mAb E40 stains the calycal processes of photoreceptors. When

The senses of hearing and balance depend on polarized epithelial cells, the hair cells of the inner ear that have a mechanosensitive hair bundle on their apical surface. The hair bundle is composed of stereocilia that are arranged in rows of increasing height. In the avian auditory papilla, four different cell-surface specializations interconnect the stereocilia. These are the tip links, the horizontal top connectors, the shaft connectors, and the ankle links (Pickles et al., 1989; Goodyear and Richardson, 1992).

The tip link is a fine extracellular filament that runs from the top of a stereocilium to the side of the adjacent taller stereocilium and is thought to gate the mechanotransducer channel (Pickles et al., 1984; Pickles and Corey, 1992). Considerable evidence supports this hypothesis. For example, reducing extracellular calcium levels to $<1 \mu \mathrm{M}$ with the calcium chelator bis(2-aminophenoxy)ethane$N, N, N^{\prime}, N^{\prime}$-tetra-acetic acid (BAPTA) rapidly abolishes transduction currents and causes tip links to disappear (Assad et al., 1991; Crawford et al., 1991). Furthermore, transduction is restored as the links regenerate after BAPTA-induced loss (Zhao et al., 1996).

The horizontal top connectors are situated a short distance below the tip links. These are plaques of hexagonally packed, short dense bars that connect each stereocilium to its neighbors. Similar junctions have been described in frogs and fishes (Jacobs

\footnotetext{
Received Jan. 12, 1999; revised March 3, 1999; accepted March 9, 1999.

This work was supported by grants from The Wellcome Trust, Defeating Deafness, and the Medical Research Council. We thank Laura Perry, Julian Thorpe, and Cecylia Malenczak for assistance, and Kevin Legan and Jonathan Gale for their helpful comments on this manuscript.

Correspondence should be addressed to Dr. Guy P. Richardson, School of Biological Sciences, The University of Sussex, Falmer, Brighton, BN1 9QG, United Kingdom.

Copyright (C) 1999 Society for Neuroscience $\quad 0270-6474 / 99 / 193761-12 \$ 05.00 / 0$
}

maculae and retinae are treated with the calcium chelator BAPTA at room temperature, the ALA disappears. BAPTAinduced loss of the ALA from the hair-bundle surface is substantially reduced by lowering the temperature to $2^{\circ} \mathrm{C}$. The ALA and ankle links reappear on the hair-bundle surface when cells are cultured for $20 \mathrm{hr}$ after BAPTA treatment. BAPTA sensitivity and recovery after BAPTA-induced loss are properties similar to those described for the tip link, a surface structure thought to gate the mechanotransducer channel. However, unlike the tip link, the ALA and ankle links are sensitive to subtilisin treatment. The results define a new component of the hair-bundle surface, with properties both common to and distinct from those of the tip link.

Key words: hair cell; photoreceptor; inner ear; retina; stereocilia; calycal process; myosin VIIA; Usher's syndrome

and Hudspeth, 1990; Nagel et al., 1991) but not in other species. In chicks, horizontal top connectors are only present on some types of hair cells; they are not found on hair cells in the extrastriolar regions of the maculae or the peripheral regions of the cristae (Goodyear and Richardson, 1992).

Shaft connectors are the third type of link found between stereocilia. These appear as very fine strands running between the membranes of adjacent stereocilia in freeze-etched preparations or tannic acid-stained material but are seen as discrete, densely stained, regularly spaced particles in ruthenium red-stained preparations (Hirokawa and Tilney, 1982; Goodyear and Richardson, 1992). The distribution of the shaft connectors on hair bundles depends on the hair-cell type. On extrastriolar hair cells of the maculae and those at the periphery of the cristae, they are distributed over the entire surface of the hair bundle, but on hair cells in other regions they are restricted to the more basal regions of the hair bundle (Goodyear and Richardson, 1992).

The ankle links are fibrous, web-like strands of material that lie in a narrow band running parallel to the apical surface, just above the point where the stereocilia insert into the top of the hair cell, and connect the stereocilia to their nearest neighbors. Ankle links are very prominent on hair cells in the auditory papilla of the lizard (Csukas et al., 1987) and are found on all hair-cell types in the bird inner ear (Goodyear and Richardson, 1992).

Previous studies have identified a component of the hair-cell surface called the hair-cell antigen (HCA), a $275 \mathrm{kDa}$ polypeptide that is exclusively localized to the apical surface of sensory hair cells within the chick inner ear (Richardson et al., 1990). Ultrastructural studies have shown that the HCA codistributes with the shaft connectors (Goodyear and Richardson, 1992). In this current study, we describe a second monoclonal antibody 

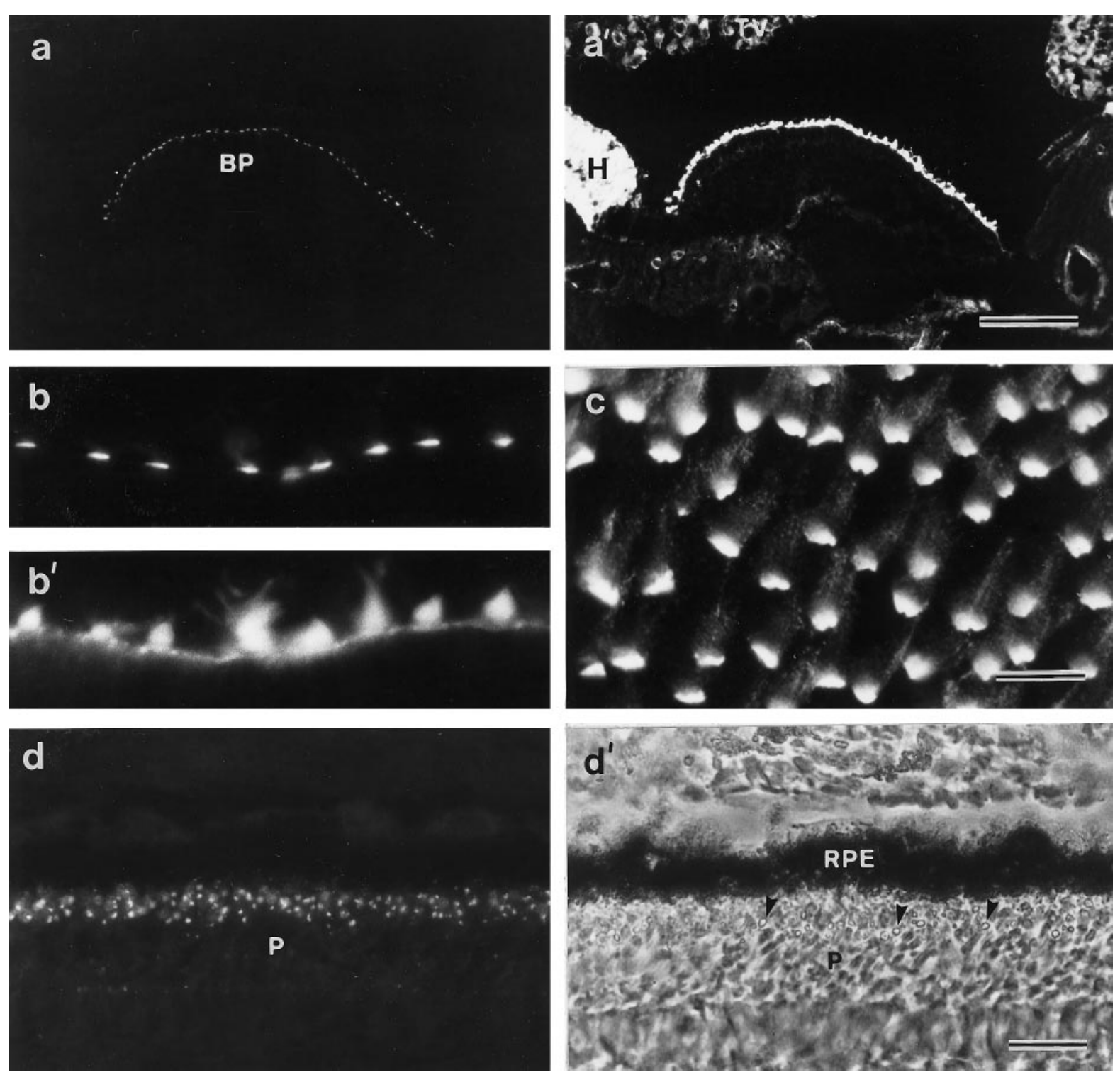

Figure 1. Localization of mAb E40 binding sites in the inner ear and the retina. $a, a^{\prime}$, Section of the cochlear duct double-labeled with mAb E40 ( $a$ ) and phalloidin $\left(a^{\prime}\right)$. Within the cochlear duct, mAb E40 is specific for the apical surface of the hair cells in the basilar papilla. Scale bar, $100 \mu \mathrm{m} . b, b^{\prime}$, High-magnification image of a cryosection from the utricular macula double-labeled with mAb E40 $(b)$ and phalloidin $\left(b^{\prime}\right)$. In sectioned material, mAb E40 staining is predominantly restricted to the base of the hair bundle. $c$, A whole-mount preparation of the utricular macula labeled with mAb E40. Although the majority of the labeling is restricted to the base of each hair bundle, punctate staining can be seen all the way up the stereocilia. Scale bar: $b, b^{\prime}, c, 10 \mu \mathrm{m} . d, d^{\prime}$, Section of the retina immunolabeled with $\mathrm{mAb} \mathrm{E} 40(d)$ and the corresponding phase-contrast image $\left(d^{\prime}\right)$. A spot of label is associated with each photoreceptor at a level close to that of the oil droplets in the cones. Arrowheads in $d^{\prime}$ indicate oil droplets. Scale bar, $20 \mu \mathrm{m} . \mathrm{BP}$, Basilar papilla; $H$, homogene cells; $P$, photoreceptors; $R P E$, retinal pigment epithelium; $T V$, tegmentum vasculosum.

$(\mathrm{mAb})$ that is highly specific for the apical surface of hair cells in the inner ear. The antigen recognized by this mAb is closely associated with the ankle links and shares some of the properties that have been described previously for the tip links.

\section{MATERIALS AND METHODS}

Production of monoclonal antibodies. Cochlear ducts were dissected from $1-2 \mathrm{~d}$ posthatch chicks in ice-cold PBS $(150 \mathrm{~mm} \mathrm{NaCl}$ and $10 \mathrm{~mm}$ sodium phosphate, $\mathrm{pH} 7.2$ ) containing $2 \mathrm{~mm}$ benzamidine, $1 \mu \mathrm{g} / \mathrm{ml}$ leupeptin, 10 $\mu \mathrm{g} / \mathrm{ml}$ pepstatin, and $0.1 \mathrm{~mm}$ phenylmethylsulphonylfluoride (PMSF). The lagenar maculae were separated from the ducts and stored frozen in liquid $\mathrm{N}_{2}$ until use. A crude membrane fraction was prepared by differential centrif ugation. The maculae were thawed on ice in PBS containing $2 \mathrm{~mm}$ benzamidine, $10 \mu \mathrm{g} / \mathrm{ml}$ leupeptin, $10 \mu \mathrm{g} / \mathrm{ml}$ pepstatin, and $1 \mathrm{~mm}$ PMSF and were homogenized using a tight-fitting Teflon glass homogenizer. The homogenate was centrif uged twice for $1 \mathrm{~min}$ at $82_{\text {gmax }}$ in a 1.5 $\mathrm{ml}$ volume to remove the otoliths and cartilaginous capsules, and the remaining supernatant then was pelleted by centrifugation at $16,000_{\text {gmax }}$ for $10 \mathrm{~min}$. The supernatant was discarded, and the pellet was washed a further three times by resuspension in PBS containing the protease inhibitor cocktail and centrifugation at $16,000_{\text {gmax }}$ for $10 \mathrm{~min}$. The final pellet was resuspended in $1.0 \mathrm{ml}$ of sterile PBS without protease inhibitors and was used to immunize a BALB/c mouse via the intraperitoneal route. The mouse was immunized on three occasions at 1 month intervals using membranes from 200-300 lagenar maculae for each immunization. After a period of 5 months, the mouse was boosted with material from a further 350 lagenar maculae, and the spleen was then used to produce monoclonal antibodies following standard methods (Kohler and Milstein, 1975). All animal procedures were performed in accordance with United Kingdom Home Office regulations. Sp2/O-Ag14 myeloma cells were used as the fusion partner, and the hybridoma cells were grown and selected in 48-well plates using hypoxanthine-aminopterin-thymidine growth medium containing 10\% Doma Drive (Immune Systems Ltd., 

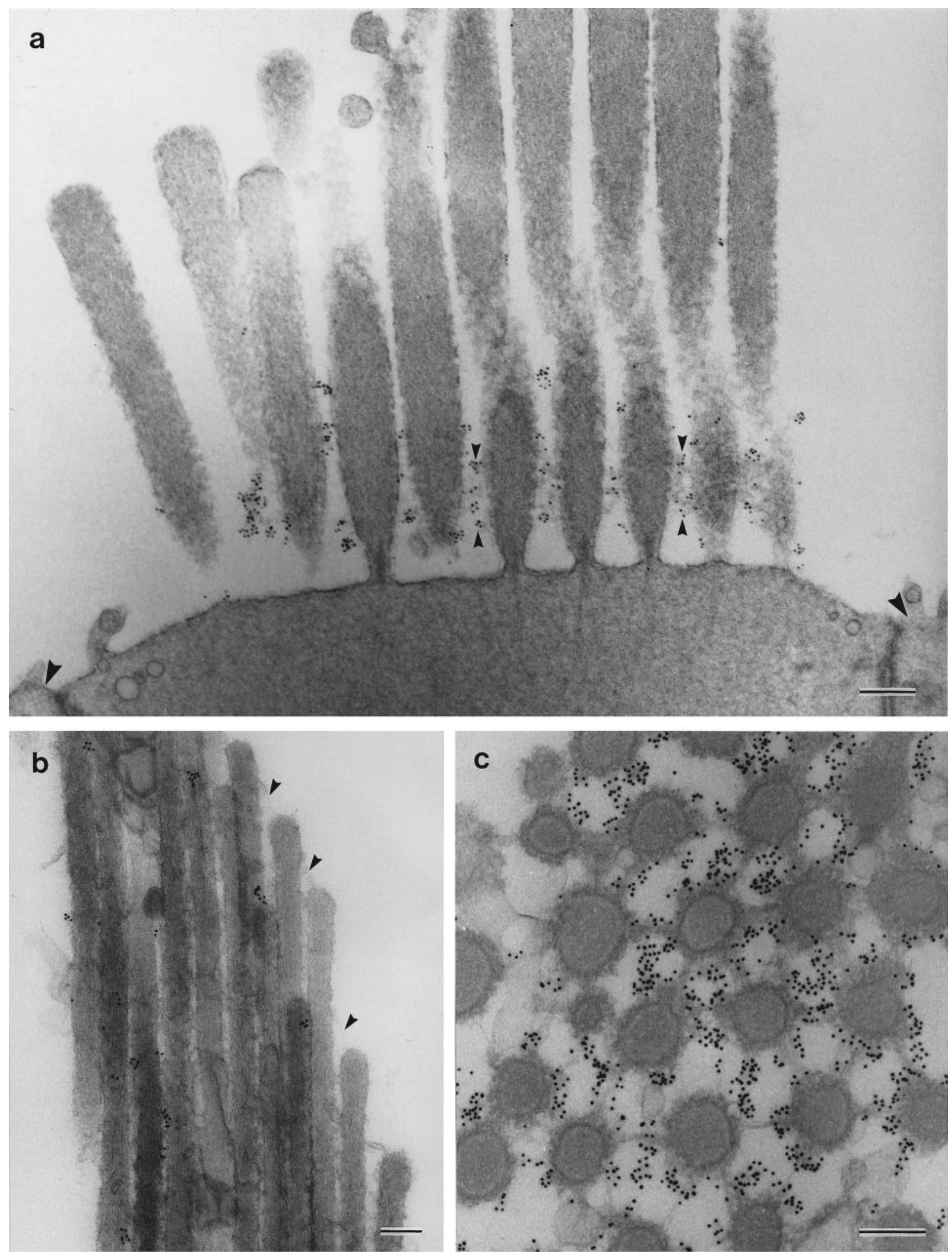

Figure 2. Ultrastructural localization of mAb E40 binding sites on hair cells. $a$, Striolar hair bundle from the utricular macula labeled with mAb E40 and $10 \mathrm{~nm}$ gold-conjugated anti-mouse IgG. Labeling is concentrated around the basal region of the hair bundle, where it is closely associated with the ankle links (small arrowheads). Large arrowheads indicate adjacent supporting cell surfaces. $b$, Extrastriolar hair bundle from the utricular macula. Labeling is seen in discrete spots along stereocilia, but the tip links (arrowheads) are unlabeled (200-nm-thick section). $c$, Section cut parallel to the apical surface of a striolar hair cell from the utricular macula at the level of the ankle links. The ankle links are heavily labeled. Samples in $b$ and $c$ were labeled with $\mathrm{mAb}$ E40, rabbit anti-mouse $\mathrm{IgG}_{1}$, and $10 \mathrm{~nm}$ gold-conjugated goat anti-rabbit IgG. Scale bars: $a, 300 \mathrm{~nm} ; b, c, 200 \mathrm{~nm}$. 

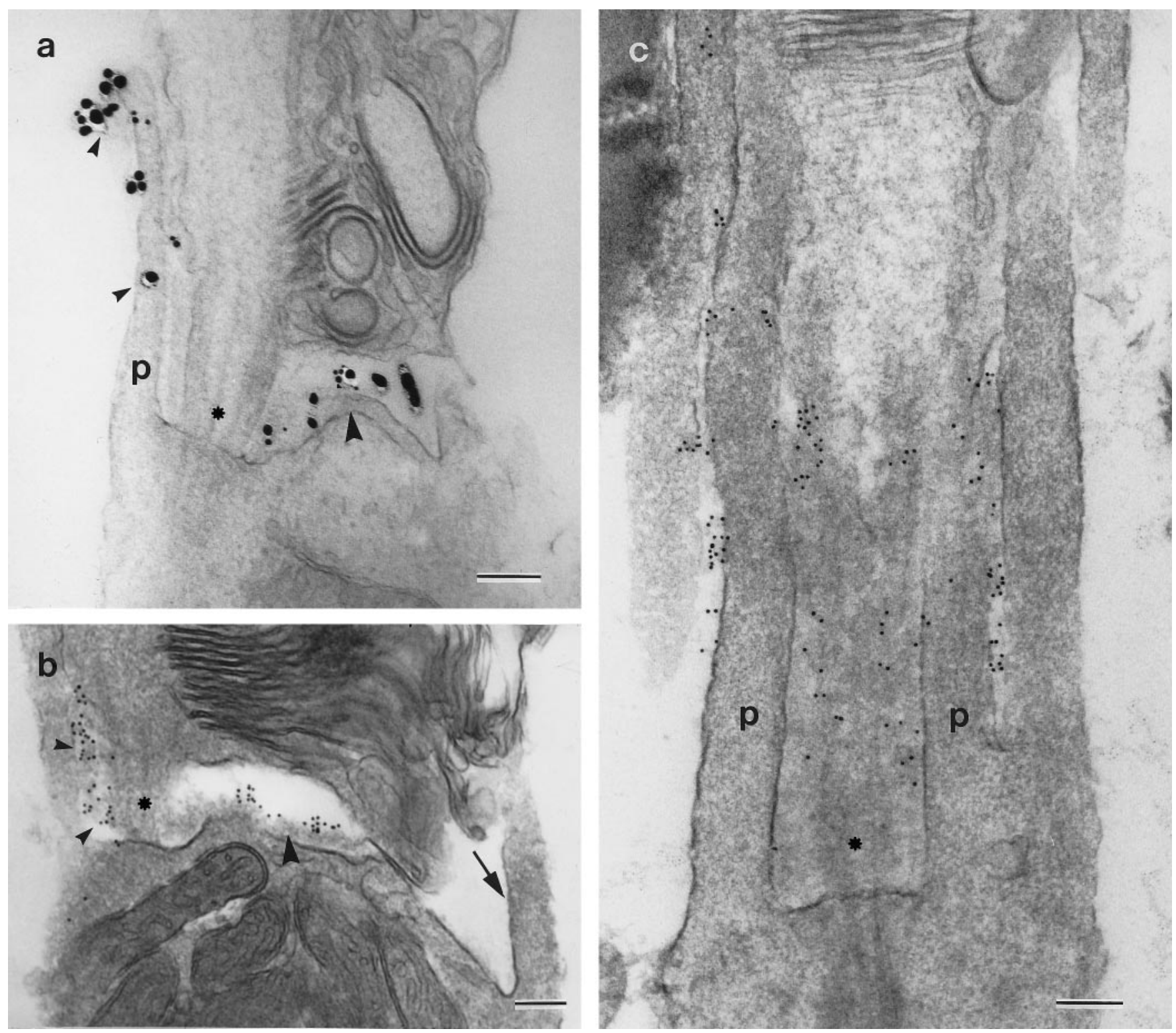

Figure 3. Ultrastructural localization of mAb E40 binding sites on rod photoreceptors. The connecting cilium is indicated by asterisks, and $p$ indicates the calycal processes. $a$, A receptor labeled with $\mathrm{mAb}$ E40 and $1 \mathrm{~nm}$ gold-conjugated goat anti-mouse IgG, followed by silver intensification. Staining is seen along the calycal process (small arrowheads) projecting from the inner segment adjacent to the connecting cilium and in the region just below the disk stack (large arrowhead). $b, c$, Photoreceptors labeled with $\mathrm{mAb} \mathrm{E} 40$, rabbit anti-mouse $\mathrm{IgG}_{1}$, and $10 \mathrm{~nm}$ gold-conjugated goat anti-rabbit IgG. In $b$, gold particles are visible between the calycal process and the connecting cilium (small arrowheads) and in the gap between the inner and outer segments (large arrowhead). Note how the calycal process on the side opposite to the connecting cilium (arrow) is unlabeled. In $c$, the section grazes the connecting cilium, revealing gold particles in the space lying between the connecting cilium and the calycal processes. Label is also seen between adjacent calycal processes. Scale bars, $200 \mathrm{~nm}$.

Bristol, UK). Supernatants were screened by immunofluorescence microscopy using cryosections prepared from sensory organs of the chick inner ear imbedded in agarose (see below). Clone E40, secreting an $\mathrm{IgG}_{1}$ class antibody, was subcloned three times by limiting dilution. Concentrations of IgG in tissue culture supernatants were determined by quantitative immunoblotting using purified mouse $\mathrm{IgG}_{1}$ as a standard.

Immunofluorescence microscopy. For screening hybridoma supernatants, pieces of cartilaginous chick skull containing the labyrinthine inner ear were immersion fixed in $3.7 \%(\mathrm{v} / \mathrm{v})$ formaldehyde in $0.1 \mathrm{M}$ sodium

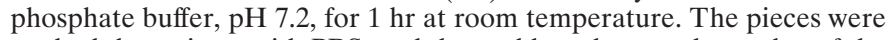
washed three times with PBS, and the cochlear ducts and maculae of the sacculus and utriculus were dissected from the labyrinth and cryoprotected by overnight incubation in PBS containing $30 \%(\mathrm{w} / \mathrm{v})$ sucrose at $4^{\circ} \mathrm{C}$. Tissue pieces were imbedded in $1 \%(\mathrm{w} / \mathrm{v})$ low-gelling point agarose (type VII; Sigma, Poole, UK) in PBS containing 18\% (w/v) sucrose, and $10-\mu$ m-thick sections were cut with a Reichert Jung Cryocut 1800 at a temperature of $-30^{\circ} \mathrm{C}$. Sections were mounted on gelatin-coated 10 -well slides and stored at $-20^{\circ} \mathrm{C}$ until use. For more detailed immunocytochemical studies, cryosections of inner-ear and other tissues from the posthatch chick and cochlear ducts from embryonic day 7 (E7) to E18 embryos were prepared as described above, except $0.025 \%$ (v/v) glutaraldehyde was added to the fixative. For whole-mount preparations, maculae were dissected from the cartilaginous head pieces, and the otolithic membranes were carefully removed before fixation. When screening hybridoma clones, undiluted culture supernatants were applied directly to the tissue sections. Otherwise, sections and whole mounts were preblocked for $1 \mathrm{hr}$ with Tris-buffered saline (TBS) (150 $\mathrm{mm} \mathrm{NaCl}$ and 10 $\mathrm{mm}$ Tris-HCl, $\mathrm{pH}$ 7.4) containing $10 \%$ (v/v) heat-inactivated horse serum (HS) before staining. Primary antibodies were allowed to react with the tissue sections or whole mounts overnight. Monoclonal anti- 

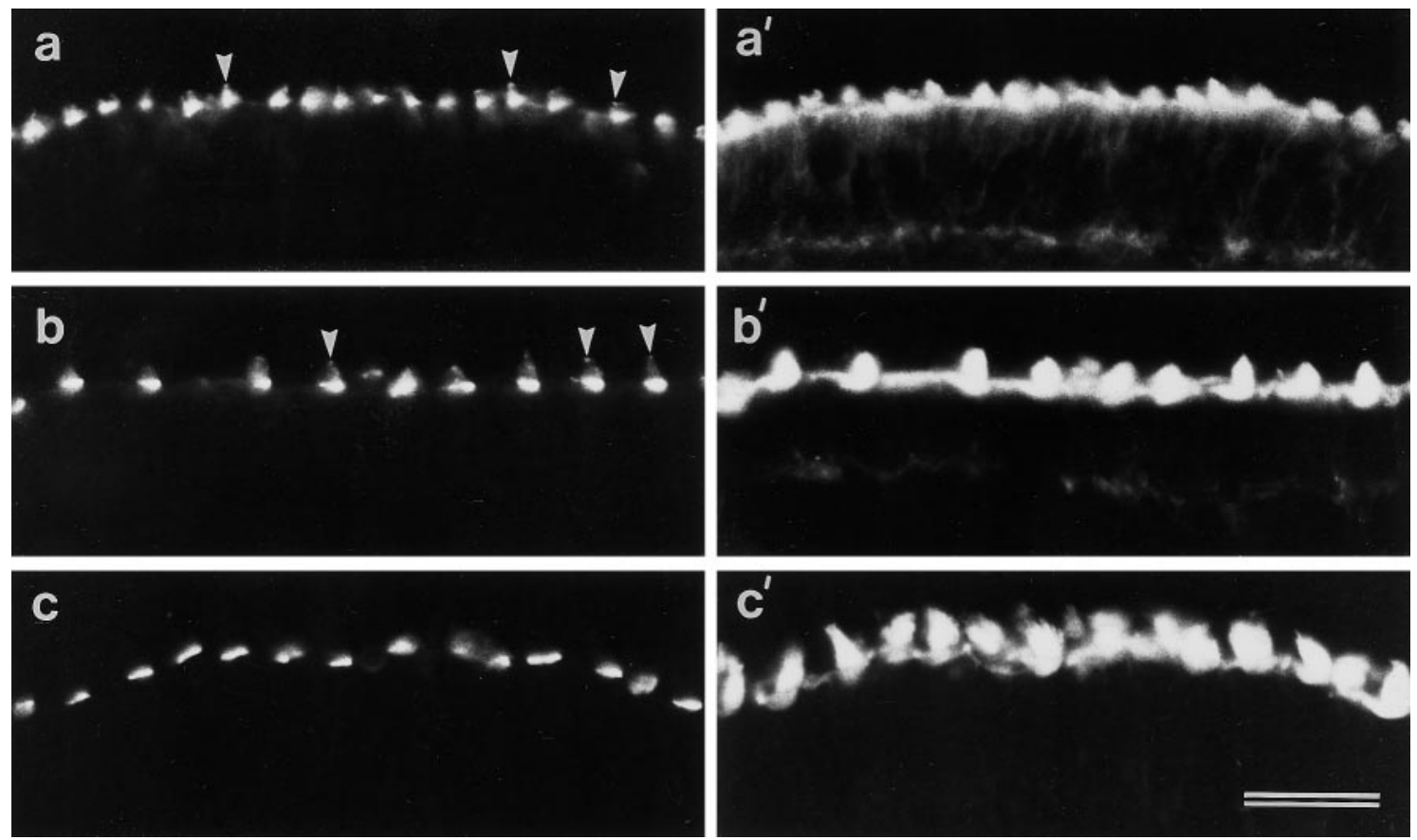

Figure 4. Distribution of mAb E40 binding sites and F-actin during development of the basilar papilla. Cryosections from papillae at the E12 ( $a$, $\left.a^{\prime}\right)$, E16 $\left(b, b^{\prime}\right)$, and $2 \mathrm{~d}$ after hatch $\left(c, c^{\prime}\right)$ stages of development double-labeled with mAb E40 $(a, b, c)$ and phalloidin $\left(a^{\prime}, b^{\prime}, c^{\prime}\right) . a, a^{\prime}, \mathrm{At} \mathrm{E} 12$, mAb E40 staining $(a)$ is distributed evenly over most of the bundle, although the tips of many hair bundles are decorated by a distinct spot of mAb E40 staining (arrowheads). $b, b^{\prime}$, At E16, mAb E40 staining $(b)$ is more concentrated at the base of the bundle, although spots of staining can be observed at the tips of many bundles (arrowheads). c, $c^{\prime}$, At $2 \mathrm{~d}$ after hatching, mAb E40 staining $(c)$ is primarily restricted to the base of the bundles, and the spots of staining seen at the tip of the bundles at earlier stages of development are no longer visible. Scale bar, $20 \mu \mathrm{m}$.

HCA and E40 supernatants were diluted 1:100 in TBS/HS before use to final concentrations of 0.5 and $0.04 \mu \mathrm{g} / \mathrm{ml}$, respectively. Control sections and whole mounts were labeled with irrelevant mouse $\mathrm{IgG}_{1}$ purified from the ascites fluid of mice carrying the plasmocytoma line MOPC $31 \mathrm{C}$ (Sigma) at a concentration of $5 \mu \mathrm{g} / \mathrm{ml}$. When screening hybridoma clones, sections were stained with FITC-conjugated rabbit anti-mouse Ig (Dako, High Wycombe, UK), followed by FITC-conjugated swine antirabbit Ig (Dako), both at a dilution of 1:100 in TBS/HS and each for a period of $2 \mathrm{hr}$. Two layers of FITC-conjugated secondary antibodies were used to improve detection sensitivity. When using the anti-HCA and E40 mAbs on sections or whole mounts, bound primary antibodies were detected using FITC-conjugated rabbit anti-mouse IgG $_{1}$ (Zymed, Cambridge, UK), followed by FITC-conjugated swine anti-rabbit Ig. When F-actin counterstaining was required, TRITC-conjugated phalloidin $(20 \mathrm{ng} / \mathrm{ml})$ was added to the second layer of fluorescent antibodies.

Immunoelectron microscopy. Tissues were prepared and immersion fixed as described above using $3.7 \%$ formaldehyde $-0.025 \%$ glutaralde-

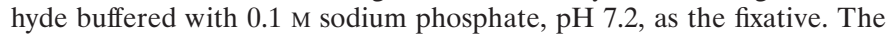
pigment epithelium was removed from the retina by dissection before fixation. This resulted in some damage to the photoreceptor outer segments but was required to obtain antibody access. After fixation, the tissue pieces were washed with PBS, preblocked in TBS/HS for $2 \mathrm{hr}$, and incubated with rotation overnight at $4^{\circ} \mathrm{C}$ in $\mathrm{E} 40$ hybridoma supernatant diluted $1: 10$ to an $\mathrm{IgG}_{1}$ concentration of $0.4 \mu \mathrm{g} / \mathrm{ml}$ with $\mathrm{TBS} / \mathrm{HS}$ containing $0.05 \%$ Tween-20 (TBS/HS/Tw). Controls were incubated in TBS/HS/Tw containing either no primary antibody or $5 \mu \mathrm{g} / \mathrm{ml}$ irrelevant mouse $\mathrm{IgG}_{1}$. After washing 10 times with $\mathrm{TBS} / \mathrm{HS}$, tissues were incubated overnight at $4^{\circ} \mathrm{C}$ on a rotator in TBS/HS/Tw containing a linker antibody, rabbit anti-mouse $\operatorname{IgG}_{1}$, at a dilution of $1: 100$. Tissue pieces were then washed 10 times in TBS/HS and incubated at $4^{\circ} \mathrm{C}$ for $4 \mathrm{~d}$, with rotation for the first $2 \mathrm{~d}$, in 10-nm-diameter colloidal gold-conjugated goat anti-rabbit IgG (British BioCell International, Cardiff, UK) diluted to $1: 20$ with $\mathrm{TBS} / \mathrm{HS} / \mathrm{Tw}$ containing $1 \mathrm{~mm}$ EDTA-1 mM sodium azide. For some samples, the linker antibody was omitted, and the bound E40 $\mathrm{mAb}$ was detected with either 10 -nm-diameter colloidal gold-conjugated goat anti-mouse $\mathrm{IgG}$ or 1-nm-diameter colloidal gold-conjugated goat anti-mouse IgG, followed by silver enhancement. After washing five times in TBS/HS/Tw/EDTA and a further five times in PBS, tissues were fixed in $2.5 \%(\mathrm{v} / \mathrm{v})$ glutaraldehyde buffered with $0.1 \mathrm{M}$ sodium cacodylate, $\mathrm{pH} 7.2$, for $1 \mathrm{hr}$, washed three times in $0.1 \mathrm{M}$ cacodylate buffer, and fixed with $1 \%(\mathrm{w} / \mathrm{v})$ osmium tetroxide in $0.1 \mathrm{M}$ sodium cacodylate for $1 \mathrm{hr}$. With some samples, $0.5 \%$ ruthenium red was added to both the glutaraldehyde and osmium tetroxide postlabeling fixatives. Tissues were then finally washed three times in cacodylate buffer and two times in distilled water before being dehydrated through an ethanol series, equilibrated in propylene oxide, and imbedded in Taab 812 resin (Taab Laboratories Ltd., Reading, UK). Blocks were polymerized at $60^{\circ} \mathrm{C}$ for $24 \mathrm{hr}$. Semithin and ultrathin sections were cut on a Reichert Ultracut E microtome. Thin sections were mounted on copper grids, counterstained with $1 \%(\mathrm{w} / \mathrm{v})$ aqueous uranyl acetate and lead citrate (Reynolds, 1963), and examined using a Hitachi 7100 transmission electron microscope.

Transmission electron microscopy: tannic acid and ruthenium red treatment. Vestibular maculae were prepared for transmission electron microscopy to assess the effects of various treatments on the different link types. Tissues were fixed with $2.5 \%(\mathrm{v} / \mathrm{v})$ glutaraldehyde in $0.1 \mathrm{M}$ sodium cacodylate, $\mathrm{pH} 7.2$, washed three times in cacodylate buffer, and fixed for $1 \mathrm{hr}$ in $1 \%(\mathrm{w} / \mathrm{v})$ osmium tetroxide in $0.1 \mathrm{M}$ sodium cacodylate. To visualize ankle links and shaft connectors, $0.5 \%(\mathrm{w} / \mathrm{v})$ ruthenium red was added to both the glutaraldehyde and osmium fixatives. To visualize the tip links and horizontal top connectors, $0.5 \%$ (w/v) tannic acid was added to the glutaraldehyde fixative. After fixation, tissues were dehydrated and imbedded as described above.

BAPTA and subtilisin treatment. Maculae from the utriculus and sacculus were dissected in HEPES-buffered (10 mM, pH 7.0) HBSS (HBHBSS), and the otolithic membranes were carefully removed, ensuring that no otoconia were left adhering to the tissue. To examine the effects of the calcium chelator BAPTA, maculae were briefly washed once in calciumfree HBHBSS before being transferred to calcium-free HBHBSS containing $5 \mathrm{~mm}$ BAPTA for $10 \mathrm{sec}, 1 \mathrm{~min}, 10 \mathrm{~min}, 20 \mathrm{~min}$, and $1 \mathrm{hr}$. Calcium-free HBHBSS was prepared in sterile plasticware from $10 \times$ concentrated calcium/magnesium-free HBSS (Life Technologies, Paisley, UK) using de-ionized water and adding magnesium to a final concentration of $0.9 \mathrm{~mm}$ and Hepes buffer, $\mathrm{pH} 7.0$, to $10 \mathrm{~mm}$. After BAPTA 

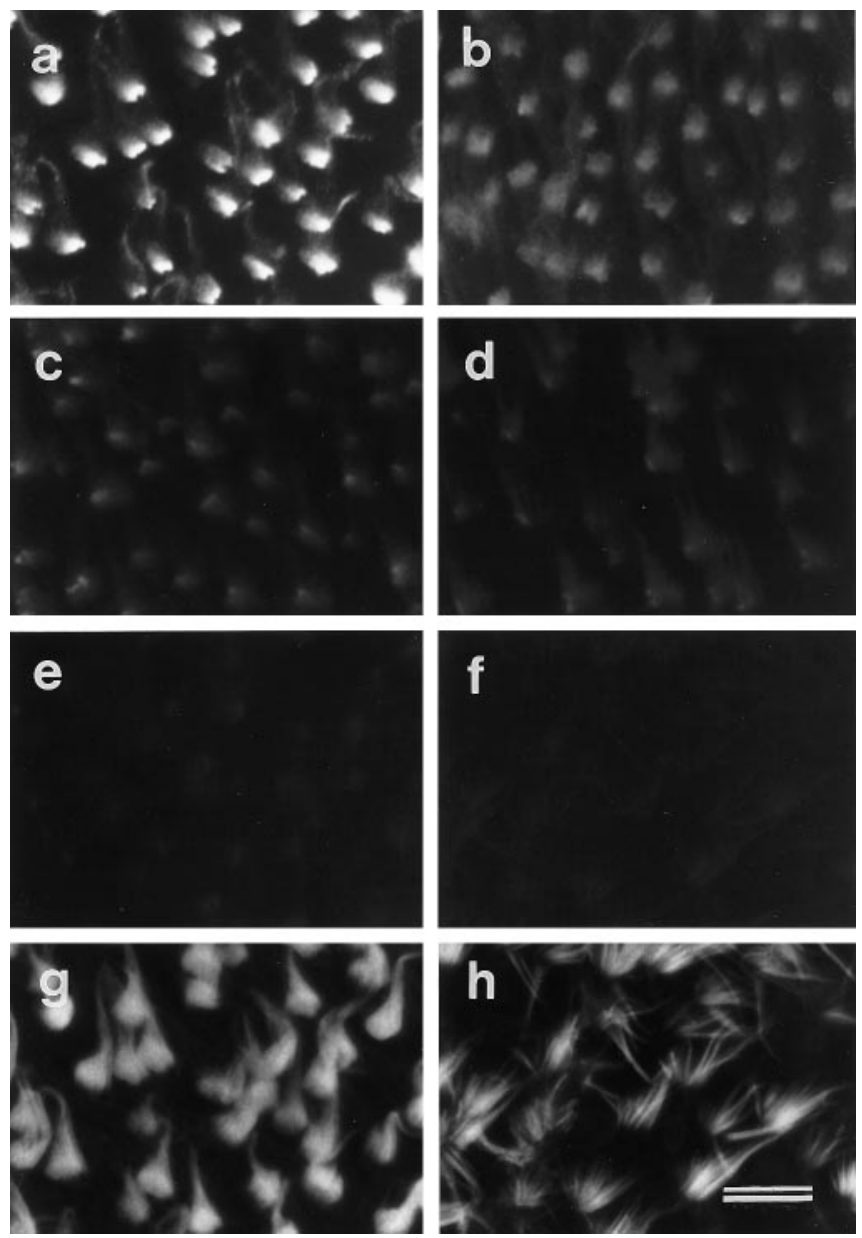

Figure 5. Effects of BAPTA treatment on mAb E40 labeling in extrastriolar regions of the utricular macula. $a$, Hair cells in a control macula incubated for $1 \mathrm{hr}$ in HBHBSS before fixation and labeling with mAb E40. Strong, basally concentrated mAb E40 labeling is seen on the hair bundles. $b-f$, Hair cells in maculae treated with $5 \mathrm{~mm}$ BAPTA for $10 \mathrm{sec}(b)$, $1 \mathrm{~min}(c), 10 \mathrm{~min}(d), 20 \mathrm{~min}(e)$, and $1 \mathrm{hr}(f)$ before fixation and labeling with mAb E40. Staining is considerably reduced after $10 \mathrm{sec}(b)$ and completely eliminated after $1 \mathrm{hr}$ of BAPTA treatment $(f) . g, h$, Phalloidin double labels of the images in $a$ and $f$, respectively. Note in $h$ how the stereocilia in the hair bundles that have been treated with BAPTA for 1 $\mathrm{hr}$ are splayed. Scale bar, $10 \mu \mathrm{m}$.

treatment, maculae were washed once in HBHBSS and fixed and processed as described above for either fluorescence or electron microscopy. Control maculae were briefly washed once in HBHBSS, incubated in HBHBSS for the same time periods as the BAPTA-treated samples, and washed once in HBHBSS before fixation. Each solution was maintained in a separate clean plastic Petri dish, and the maculae were transferred from one solution to the next using clean forceps for each transfer. A similar protocol was used to test the effects of BAPTA on small pieces of isolated retina from which the pigment epithelium had been removed, except only a 20 min BAPTA exposure time point was examined. For BAPTA treatment of maculae at $2^{\circ} \mathrm{C}$, the entire procedure was performed in a cold room using prechilled solutions and exposure times of $20 \mathrm{~min}, 2 \mathrm{hr}$, and $4 \mathrm{hr}$. For tissue culture experiments, maculae were first dissected under sterile conditions and then treated with HBHBSS or calcium-free HBHBSS containing 5 mM BAPTA as described above for 20 min. Tissue was then incubated in DMEM with Earle's salts containing $10 \%$ fetal bovine serum for $20 \mathrm{hr}$ at $37^{\circ} \mathrm{C}$ in a $95 \%$ air $-5 \% \mathrm{CO}_{2}$ atmosphere, washed three times in HBHBSS, and fixed as described above for either fluorescence or immunoelectron microscopy. To examine the effects of subtilisin, maculae were dissected in HBHBSS as described above, incubated in a $50 \mu \mathrm{g} / \mathrm{ml}$ solution of subtilisin (Protease
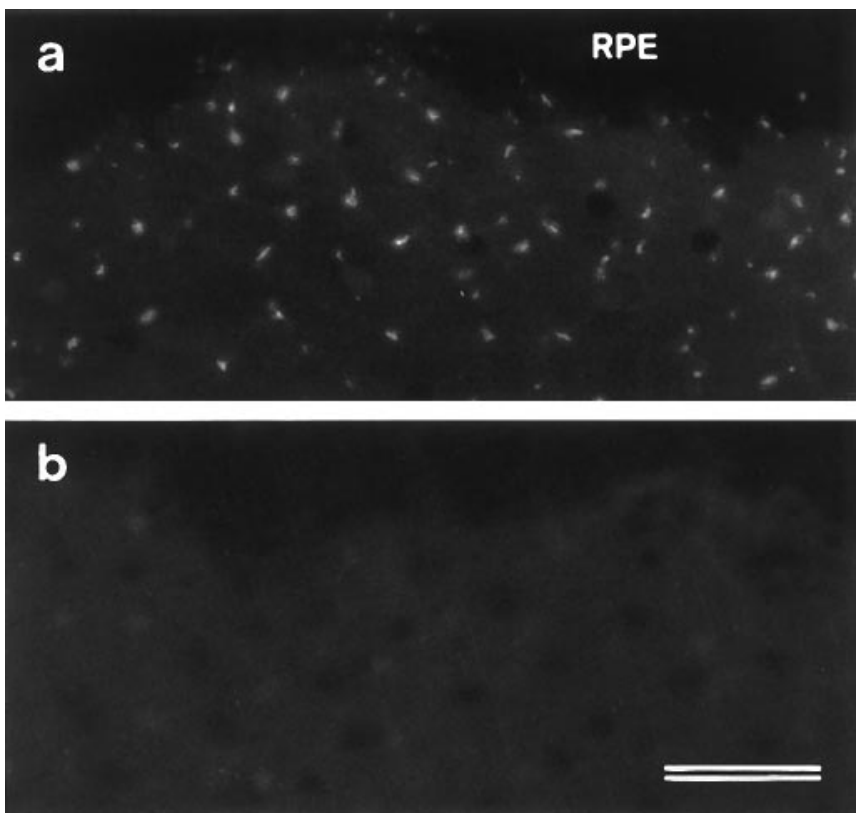

Figure 6. Effects of BAPTA treatment on $\mathrm{mAb}$ E40 labeling in retina whole mounts. $a$, Control retina incubated in HBHBSS for $20 \mathrm{~min}$ before fixation and labeling with $\mathrm{mAb}$ E40. Punctate staining of the photoreceptors is observed in areas from which the retinal pigment epithelium (RPE) has been removed before treatment. $b$, Retina incubated in 5 mM BAPTA for $20 \mathrm{~min}$ before fixation and labeling with mAb E40. Note the loss of labeling. The dark area across the top of each micrograph is a region covered by the retinal pigment epithelium. Scale bar, $20 \mu \mathrm{m}$.

type XXIV; Sigma) in HBHBSS for $20 \mathrm{~min}$ at room temperature, washed briefly in HBHBSS, and fixed as described above.

\section{RESULTS}

\section{mAb E40 antibody stains hair-cell bundles and photoreceptors}

Cryosections of the early posthatch cochlear duct double-labeled with $\mathrm{mAb}$ E40 and rhodamine phalloidin reveal that mAb E40 specifically labels the hair cells in the basilar papilla (Fig. 1a, $a^{\prime}$ ). The E40 mAb labels hair cells in both the auditory (Fig. 1a) and vestibular epithelia of the chick inner ear (Fig. 1b,c). The epitope recognized by mAb E40 is concentrated around the basal region of each hair bundle, close to where the stereocilia insert into the cuticular plate (Fig. $1 b, b^{\prime}$ ). In whole-mount preparations stained with $\mathrm{mAb}$ E40, punctate labeling can also be seen distributed all along the stereocilia, up to the top of the hair bundle, in addition to the staining observed around the base of the hair bundle (Fig. 1c). This punctate labeling is clearly observed in whole-mount preparations but is less apparent in cryosectioned material. mAb E40 labels hair cells from the auditory and vestibular epithelia of the chick inner ear in an identical manner, irrespective of their location within the different epithelia. A similar staining pattern is observed with hair cells from the proximal and distal regions of the papilla, from the striolar and extrastriolar regions of the macula, and from the central and peripheral regions of the cristae. Staining was not observed in sections or whole mounts labeled with an irrelevant $\mathrm{IgG}_{1}$ antibody at $5 \mu \mathrm{g} / \mathrm{ml}$, a concentration 125-fold higher than that of the diluted mAb E40 tissue culture supernatant. mAb E40 supernatants can be used to stain hair cells at a concentration as low as $4 \mathrm{ng} / \mathrm{ml}$ with no loss in staining intensity. 

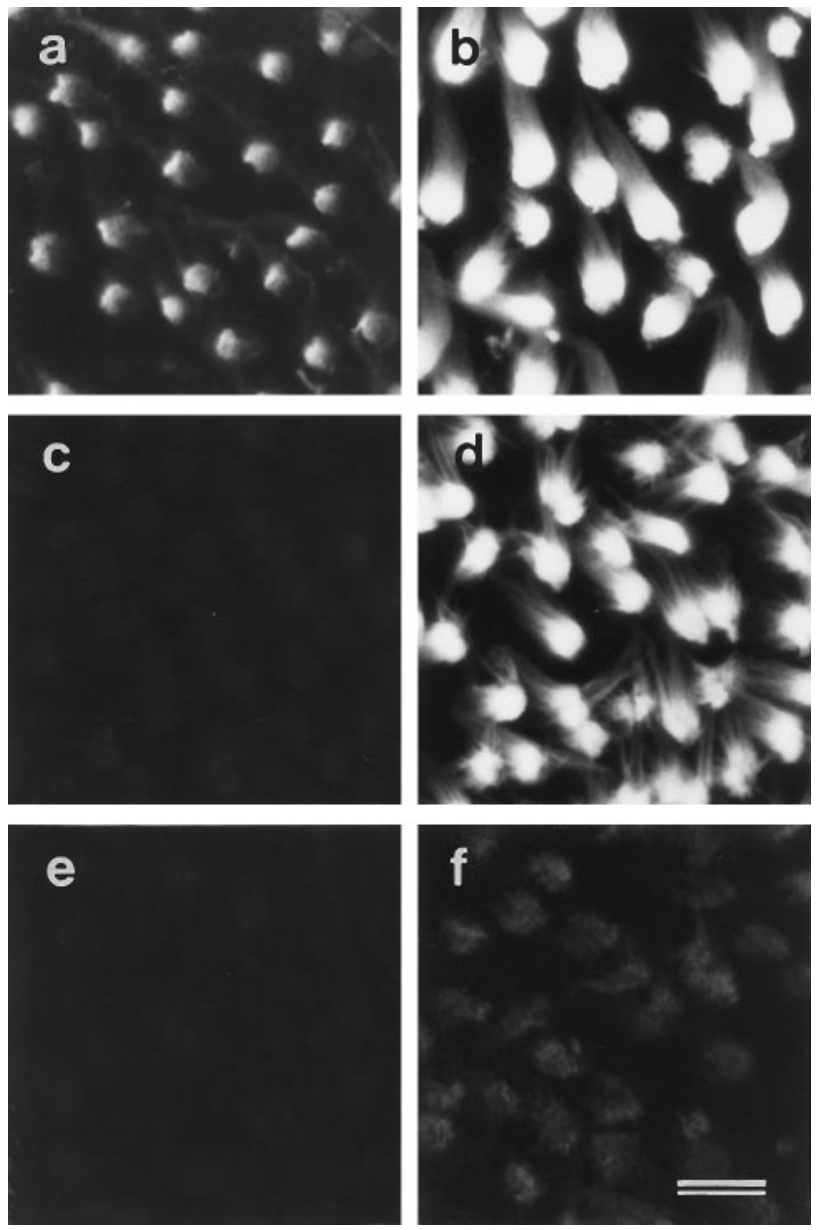

Figure 7. Effects of BAPTA and subtilisin on mAb E40 $(a, c, e)$ and anti-HCA labeling $(b, d, f)$ in extrastriolar regions of utricular maculae. $a$, $b$, Control samples incubated in HBHBSS for $60 \mathrm{~min} . c, d$, Samples incubated in $5 \mathrm{~mm}$ BAPTA for $60 \mathrm{~min} . e, f$, Samples incubated in $50 \mu \mathrm{g} / \mathrm{ml}$ subtilisin for $20 \mathrm{~min}$. In control maculae $(a, b)$, both mAb E40 $(a)$ and monoclonal anti-HCA antibody $(b)$ label hair bundles strongly. After $1 \mathrm{hr}$ of BAPTA treatment, mAb E40 antigen no longer stains the cell surface $(c)$, whereas the distribution of the hair-cell antigen is unchanged $(d)$, although the hair bundles are splayed. After 20 min exposure to subtilisin, the mAb E40 staining can no longer detected $(e)$, and only traces of the HCA remain $(f)$. Scale bar, $10 \mu \mathrm{m}$.

Cryosections of a number of other tissues from the posthatch chicken were stained with mAb E40 to determine the general distribution of the antigen. Immunoreactivity was detected by immunofluorescence microscopy in the retina but not in brain, gizzard, gut, kidney, heart, liver, lung, or muscle. In the chick retina, a single spot of staining is associated with each photoreceptor (Fig. $1 d, d^{\prime}$ ). In the cones, this spot lies close to the oil droplet that is located at the distal end of the inner segment. mAb E40 does not stain hair bundles in the organ of Corti of the early neonatal mouse or the inner ear of teleost fish.

The epitope recognized by $\mathrm{mAb}$ E40 cannot be detected in resin-embedded tissues; therefore, preembedding methodology was used to examine its distribution at the ultrastructural level. This technique reveals that the epitope recognized by mAb E40 is located on the extracellular surface of the hair bundle (Fig. $2 a, c)$. Although a few colloidal gold particles are associated directly with the surface coat of the sterecilia, the E40 epitope is highly concentrated in the vicinity of the ankle links (Fig. 2a,c) and is therefore referred to as the ankle-link antigen. The ALA is not detected on the apical, nonstereociliary surface of the hair cell and is restricted to the hair bundle (Fig. 2a). Immunogold labeling is also observed higher up the stereociliar bundle but tip links, when visible in these preparations, are not labeled (Fig. 2b). In the retina, the epitope recognized by mAb E40 localizes to the calycal processes that extend from the distal region of the inner segment and ensheathe the proximal part of the outer segment (Fig. $3 a-c$ ). Immunogold labeling is more strongly associated with calycal processes that are in close proximity to the connecting cilium (Fig. 3b,c). The epitope is also found beneath the disk stack, at the interface between the inner and outer segments (Fig. $3 a, b)$. Immunogold labeling was not observed when irrelevant $\mathrm{IgG}_{1}$ was used at a concentration 12.5-fold higher than that of the diluted mAb E40 supernatant used these experiments.

\section{The distribution of the ankle-link antigen on the hair bundle changes during development}

The ALA is expressed early during hair-cell development. In the basilar papilla, ALA expression is first seen on hair cells in the distal tip of the epithelium at E7 (data not shown). Cryosections that have been double-labeled with $\mathrm{mAb}$ E40 and phalloidin show how the distribution of the ALA on hair bundles changes between E12 and $2 \mathrm{~d}$ after hatching (Fig. 4). At E12, the ALA is distributed evenly over most of the bundle surface, although a discrete spot of staining is often seen concentrated at the very tip of the bundle (Fig. 4a). At E16, the ALA becomes primarily restricted to the basal half of each hair bundle, although a spot of the ALA is still apparent at the top of some hair cells (Fig. 4b). By the early posthatch stage, the ALA is mostly concentrated in a narrow zone around the base of each bundle (Fig. 4c). The height of this narrow band where the ALA is concentrated in the early posthatch papilla is less that the height of the hair bundles at E12, indicating that restriction toward the hair-bundle base is not simply a consequence of the bundle growing at its tip.

\section{The ankle-link antigen is lost after BAPTA or subtilisin treatment}

The ALA is rapidly lost from the hair-bundle surface when maculae are exposed to the calcium chelator BAPTA at room temperature (Fig. 5). BAPTA exposure times as short as $10 \mathrm{sec}$ cause a significant reduction in the subsequent staining observed with mAb E40 relative to controls (Fig. 5a,b). Progressively more of the ALA is lost as the BAPTA exposure time is increased to $60 \mathrm{sec}$ (Fig. 5c) and $10 \mathrm{~min}$ (Fig. $5 d$ ), but it is only completely removed from hair bundles in maculae that have been exposed to BAPTA for $>20$ min (Fig. $5 e, f$ ). Phalloidin staining reveals that the bundles in samples that have been exposed to BAPTA for longer than $20 \mathrm{~min}$ have a distinctly splayed appearance relative to control samples (Fig. $5 g, h$ ). In the retina, treatment with BAPTA for $20 \mathrm{~min}$ also leads to a loss of staining with the E40 mAb (Fig. 6a,b).

Although BAPTA treatment results in the rapid loss of the ALA from the hair-cell surface, it has no effect on the distribution of the HCA. Treatment with BAPTA for 60 min eliminates all immunoreactivity for mAb E40 (Fig. 7a,c) but has no effect on anti-HCA staining (Fig. 7b,d). Tip links are known to be sensitive to BAPTA treatment but are insensitive to treatment with subtilisin, a protease that is used frequently as a means of removing 

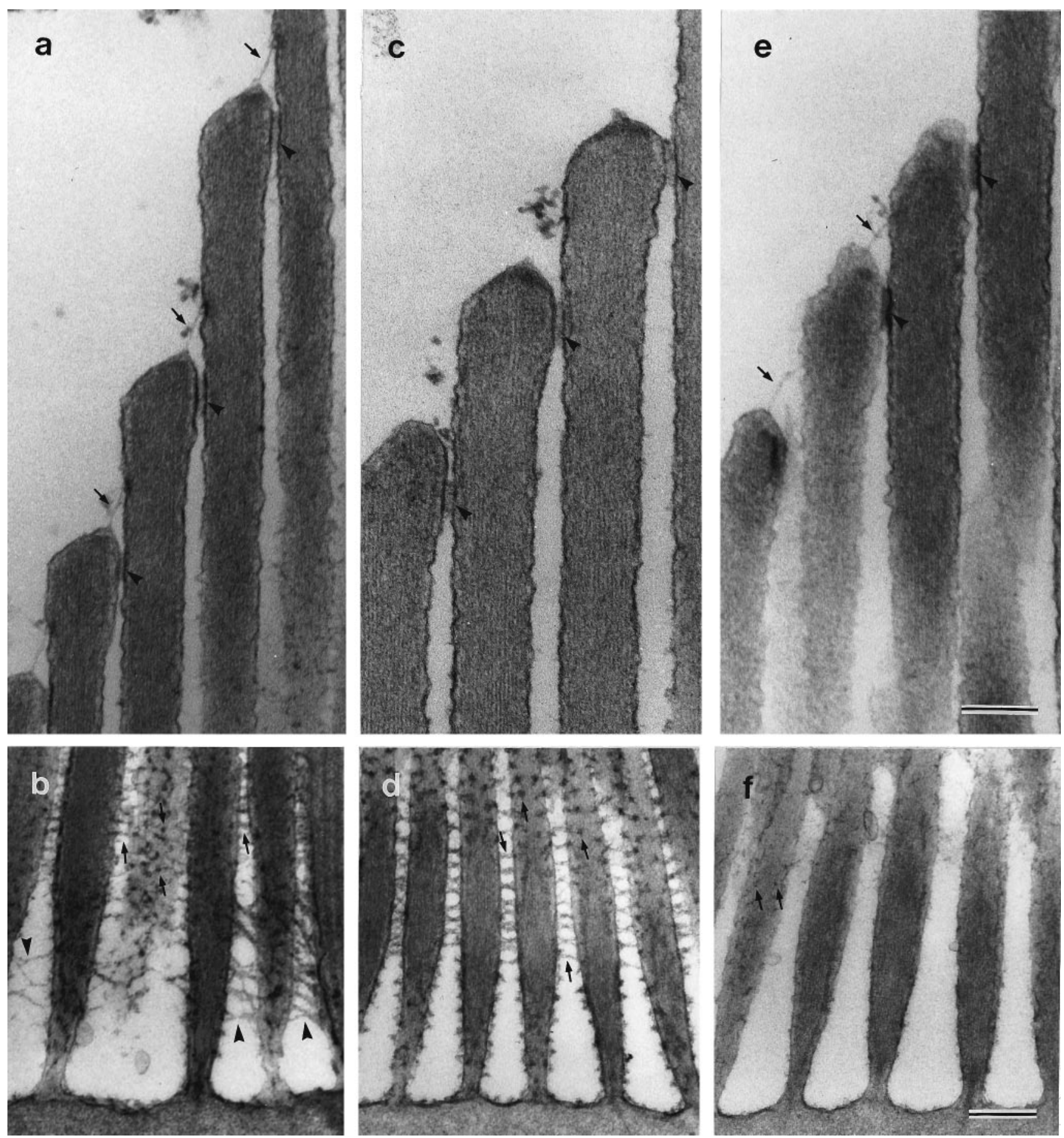

Figure 8. Effects of BAPTA and subtilisin on hair-bundle links and connectors. Ultrastructural appearance of the upper regions of tannic acid-stained striolar hair bundles $(a, c, e)$ and the basal regions of ruthenium red-stained extrastriolar hair bundles $(b, d, f)$ in utricular maculae incubated with HBHBSS $(a, b)$, BAPTA $(c, d)$, and subtilisin $(e, f)$. In $a, c$, and $e$, arrows indicate tip links, and arrowheads indicate horizontal top connectors. In $b, d$, and $f$, arrows indicate shaft connectors, and arrowheads indicate ankle links. $a, b$, In controls incubated in HBHBSS for 20 min, tip links, horizontal top connectors, shaft connectors, and ankle links can all be seen. $c, d$, After treatment with 5 mM BAPTA for 20 min, tip links and ankle links can no longer be observed, but horizontal top links and shaft links are still visible. $e$, $f$, After treatment with $50 \mu \mathrm{g} / \mathrm{ml}$ subtilisin for 20 min, tip links and horizontal top links are still present, only a few remnants of the shaft links remain, and ankle links are absent. Scale bars: $a-f, 300 \mathrm{~nm}$.

the overlying extracellular matrix when preparing maculae for electrophysiology experiments. Treating vestibular maculae with $50 \mu \mathrm{g} / \mathrm{ml}$ subtilisin for $20 \mathrm{~min}$ at room temperature before fixation completely eliminates mAb E40 immunoreactivity (Fig. 7e). The amount of staining observed with the monoclonal anti-HCA antibody is also substantially reduced (Fig. $7 f$ ). These results indicate that the HCA and the ALA are both subtilisin-sensitive, whereas only the ALA is lost in response to calcium chelation.

\section{Effects of BAPTA and subtilisin on hair-bundle links}

The four different types of cell-surface specializations that interconnect the stereocilia in the basilar papilla and the striolar 

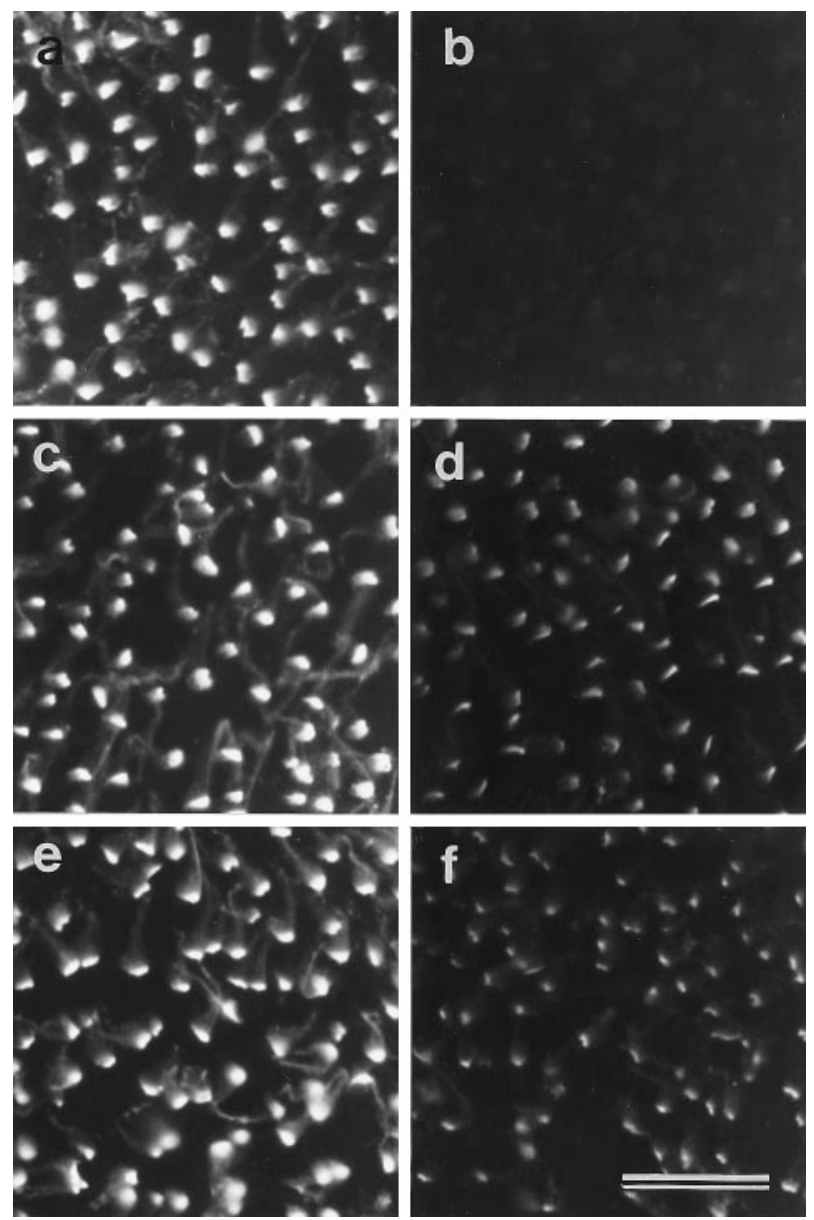

Figure 9. Temperature dependence of the effects of BAPTA treatment on $\mathrm{mAb}$ E40 labeling in extrastriolar regions of the utricular macula. $a, b$, Maculae stained with mAb E40 after a 20 min incubation in $\operatorname{HBHBSS}(a)$ or $5 \mathrm{~mm}$ BAPTA $(b)$ at room temperature. $c, d$, Maculae stained with mAb E40 after a 20 min incubation in $\operatorname{HBHBSS}(c)$ or 5 mM BAPTA $(d)$ at $2^{\circ} \mathrm{C}$. Although staining is reduced in the tissue treated with BAPTA at $2^{\circ} \mathrm{C}$ compared with the control tissue, labeling is much stronger than that seen after BAPTA treatment at room temperature $(b)$. e, $f$, Maculae stained with mAb E40 after a $4 \mathrm{hr}$ incubation in $\operatorname{HBHBSS}(e)$ or $5 \mathrm{~mm}$ BAPTA $(f)$ at $2^{\circ} \mathrm{C}$. The degree of labeling observed after BAPTA treatment for $4 \mathrm{hr}$ at $2^{\circ} \mathrm{C}(f)$ is similar to that seen after $20 \mathrm{~min}$ at $2^{\circ} \mathrm{C}(d)$. Scale bar, $20 \mu \mathrm{m}$.

regions of the maculae can be visualized with transmission electron microscopy in tissue samples that have been stained with either tannic acid (Fig. 8a,c,e) to visualize the tip links and horizontal top connectors, or ruthenium red (Fig. $8 b, d, f$ ) to visualize the shaft connectors and ankle links. In samples that have been treated with BAPTA, both the tip links (Fig. 8c) and the ankle links (Fig. $8 d$ ) are lost, whereas the horizontal top connectors (Fig. 8c) and shaft connectors (Fig. 8d) remain intact and appear similar to those observed in controls (Fig. 8a,b). Although it can be difficult to distinguish ankle links from shaft connectors in the basal region of the hair bundle in ruthenium red-stained preparations, the differential sensitivity of these two link types to BAPTA treatment (Fig. 8, compare $b, d$ ) clearly reveals that they are distinct structures. After subtilisin treatment, both the tip links and the horizontal top connectors remain (Fig. $8 e$ ); however, ankle links are no longer visible, and only traces of shaft connector material can be seen (Fig. $8 f$ ).

\section{Effect of BAPTA on the ankle-link antigen is reduced at $2^{\circ} \mathrm{C}$}

BAPTA treatment for $20 \mathrm{~min}$ at room temperature results in the loss of almost all the ALA from the hair-cell surface (Fig. 9a, $b$ ), but a considerable amount remains associated with the hair bundle when BAPTA treatment is performed at $2^{\circ} \mathrm{C}$ (Figs. $9 c, d$, $11 a, b)$. Although a proportion of the ALA is removed from the cell surface on treatment with BAPTA for $20 \mathrm{~min}$ at $2^{\circ} \mathrm{C}$, extending the time of treatment to $4 \mathrm{hr}$ at $2^{\circ} \mathrm{C}$ does not lead to a further loss (Fig. 9e,f). The reduction in $\mathrm{mAb} \mathrm{E} 40$ staining that is observed when maculae are exposed to BAPTA at low temperature is associated with a loss of the ALA from all regions of the hair bundle. Transmission electron microscopy confirms that most of the ankle links are retained when BAPTA treatment is performed at $2^{\circ} \mathrm{C}$ (Fig. 11b).

\section{Recovery of the ankle-link antigen on the cell surface after BAPTA-induced loss}

The ALA reappears on the hair-bundle surface if maculae are placed in culture for $20 \mathrm{hr}$ after exposure to BAPTA (Figs. 10, $11 c-f)$. As described above, $20 \mathrm{~min}$ exposure to BAPTA at room temperature leads to an almost complete loss of the ALA from the hair bundle relative to controls (Figs. 10a,b, 11c,d). After 20 hr culture in vitro, the ALA reappears on the hair-bundle surface in the BAPTA-treated maculae, although not to the same levels as those observed in the HBHBSS-treated controls that have been maintained in culture for the same time period (Figs. 10c,d, $11 e, f)$. Reappearance of ankle links also occurs along with recovery of the ALA (Fig. 11f).

\section{DISCUSSION}

The results of this study describe mAb E40, a monoclonal antibody that defines a BAPTA-sensitive component of the hairbundle surface, the ALA. The ALA is an epitope that is closely associated with the ankle links but is also found higher up the bundle. The E40 $\mathrm{mAb}$ does not react with any proteins on Western blots, and attempts to immunoprecipitate the ALA from extracts of maculae that have been either metabolically labeled with ${ }^{35} \mathrm{~S}$ or surface labeled with ${ }^{125} \mathrm{I}$ using lactoperoxidase have not yet proven successful. However, the properties of the ALA clearly indicate that it is distinct from the previously described HCA (Richardson et al., 1990). First, the ALA is restricted to the hair bundle, whereas the HCA is found on both the hair-bundle surface and the apical, nonstereociliary surface of the hair cell (Richardson et al., 1990). Second, the ALA has a similar distribution on all hair cells examined, whereas the distribution of the HCA on the hair-cell surface varies systematically according to hair-cell type (Goodyear and Richardson, 1992). Third, the ALA is lost on exposure to the calcium chelator BAPTA, whereas the HCA is not. On the basis of this evidence, the E40 and anti-HCA mAbs define two different components of the apical surface of the hair cell.

Tip links are rapidly lost when hair cells are exposed to BAPTA, and this loss correlates with the rapid failure of mechanotransduction that is caused by calcium chelation (Assad et al., 1991; Crawford et al., 1991). Although the ALA and the ankle links are lost in response to BAPTA treatment, it is unlikely that either are directly involved in the transduction process because they are degraded by brief exposure to concentrations of subtilisin routinely used for physiological studies of mechanotransduction. Also, tip links are lost from the cell surface within $10 \mathrm{sec}$ in response to BAPTA treatment (Assad et al., 1991), whereas it 

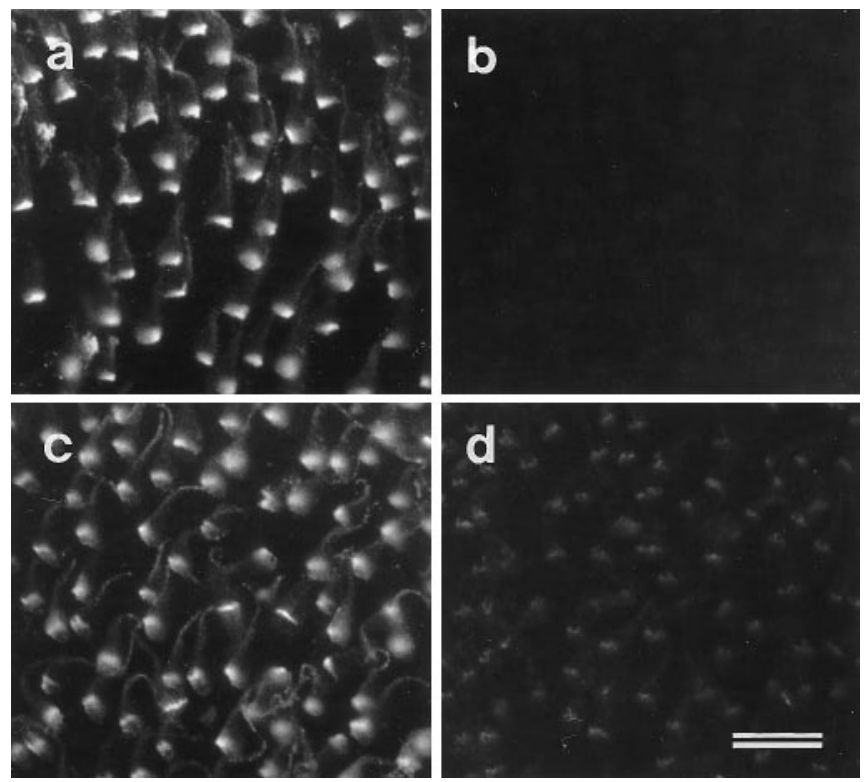

Figure 10. Recovery of mAb E40 labeling after BAPTA-induced loss. $a$, Control macula stained with $\mathrm{mAb}$ E40 after 20 min incubation in $\mathrm{HBH}$ BSS. $b$, BAPTA-treated ( $5 \mathrm{~mm}, 20 \mathrm{~min}$ ) macula stained with $\mathrm{mAb}$ E40. Note that only very weak labeling can be detected. $c$, Control, HBHBSStreated macula after $20 \mathrm{hr}$ in vitro stained with mAb E40. $d$, BAPTAtreated (5 mM, $20 \mathrm{~min})$ macula stained with $\mathrm{mAb}$ E40 after $20 \mathrm{hr}$ in vitro. $\mathrm{mAb}$ E40 staining has reappeared but not to the same level as in the control $(b)$. Scale bar, $10 \mu \mathrm{m}$.

takes considerably longer ( $>10 \mathrm{~min}$ ) for all the ALA to disappear entirely. However, there may be two pools of ALA, one that binds to the cell membrane in a calcium dependent manner and another that is subject, like members of the cadherin family of cell-cell adhesion molecules (Takeichi, 1990), to proteolysis in the absence of calcium and is thereby released from the cell membrane. The ALA that is rapidly lost from the cell surface within the first $10 \mathrm{sec}$ of BAPTA treatment at room temperature and the ALA that is lost in response to BAPTA treatment at $2^{\circ} \mathrm{C}$ may represent a pool that binds to the cell surface in a calciumdependent manner. The fraction that remains associated with the hair bundle at $2^{\circ} \mathrm{C}$ in the presence of BAPTA may not be released from the membrane unless subject to proteolysis, a process that is likely to be temperature-sensitive.

Although previous studies with frog hair cells have reported that ankle links are sensitive to subtilisin treatment (Jacobs and Hudspeth, 1990; Assad et al., 1991), their sensitivity to calcium chelation, like tip links, has been hitherto unrecognized (Neugebauer and Thurm, 1987). Furthermore, like tip links (Zhao et al., 1996), ankle links and the ALA reappear on the cell surface after loss as a result of calcium chelation. Although the amount of ALA on the hair-bundle surface does not recover to pre-BAPTA exposure levels, these observations further substantiate the suggestion (Sobkowicz et al., 1992) that hair cells can undergo some degree of self-repair after sublethal damage. Although tip links can be distinguished from the ankle links and the ALA on the basis of their relative sensitivities to subtilisin, they may be related molecules or the tip link might be a subtilisin-insensitive derivative of either the ankle link or the ALA. It has been suggested that the tip links are derived from lateral links observed near the top of the extremely short bundles of nonranked stereocilia found in the very early stages of hair-cell development and that those lateral links that do not go on to form tip links stay at the bundle base during growth, remaining as ankle links (Pickles et al., 1991). Although the results of our study indicate that the ALA is distributed over most of the surface of immature hair bundles and that consolidation around the bundle base is not entirely attributable to growth at the tip of the bundle, a spot of antigen does remain transiently associated with the bundle tip as it grows. The precise relationship between this material located at the top of the bundle and the developing tip links has yet to be determined, but the observation does lend support to the suggestion that tip links may derive from ankle-link-like material (Pickles et al., 1991).

The function of the ankle links and of the other lateral-link types, the shaft connectors, and the horizontal top connectors, has yet to be determined, but it is generally assumed that they maintain the stereocilia as a coherent unit or transmit forces across the bundle. The results of this study indicate that these lateral links and the tip links can all be distinguished from one another on the basis of antibody reactivity and their differential sensitivity to BAPTA and subtilisin. The four link types are therefore likely to be distinct molecular entities, which may have different or overlapping functions, and it should be possible to use the differential sensitivity of the four link types to BAPTA and subtilisin to assess their contribution to the micromechanical properties and integrity of the hair bundle. Prolonged BAPTA treatment causes splaying of the stereocilia, suggesting either tip links or ankle links or both, are important for holding the stereocilia together. A recent study with sea anemones (Watson et al., 1998) has shown that treatment with the calcium chelator EGTA leads to the splaying of hair bundles in the cnidocil complex and that an EGTA-soluble fraction can reverse or repair this splaying in a cycloheximide-insensitive manner, suggesting that components with properties similar to the ALA and tip links can directly bind to and cross-link stereocilia. Two mAbs have also been described that recognize different components of the cnidocil apparatus in Hydra (Golz and Thurm, 1992), and it would be interesting to determine whether either of the epitopes recognized by these mAbs are sensitive to calcium chelation.

The ALA is also associated with another sensory cell type, the photoreceptor, and localizes to the ciliary calyx, a ring of microvilli that project from the distal end of the inner segment and surround both the connecting cilium and the proximal end of the outer segment. It is not known whether the molecules recognized by $\mathrm{mAb}$ E40 in the retina and ear are the same or merely share the same epitope, the ALA. However, they share similar properties; in the eye and the ear, they are both sensitive to BAPTA treatment and are localized on the extracellular surface of the cell. In the eye, the ALA may be associated with cell-surface specializations that link the calycal microvilli either to each other, the connecting cilium, or the outer segment. Although links have been described between the calycal processes and the outer segment in frogs (Fetter and Corless, 1987), it is not known whether such structures exist in the chick.

In hair cells and photoreceptors, the ALA localizes close to regions where the product of the gene defective in Usher's IB syndrome, myosin VIIA (Weil et al., 1995), is concentrated. In frog hair bundles, myosin VIIA is concentrated around the bundle base, at the level of the ankle links, and it has been suggested that it interacts with the cytoplasmic tail of a putative, transmembrane ankle-link protein (Hasson et al., 1997). In rodent and human photoreceptors, myosin VIIA localizes to the connecting cilium (Liu et al., 1997). Myosin VIIA has not yet been described in the ciliary calyx of these species, but the calyx is poorly 

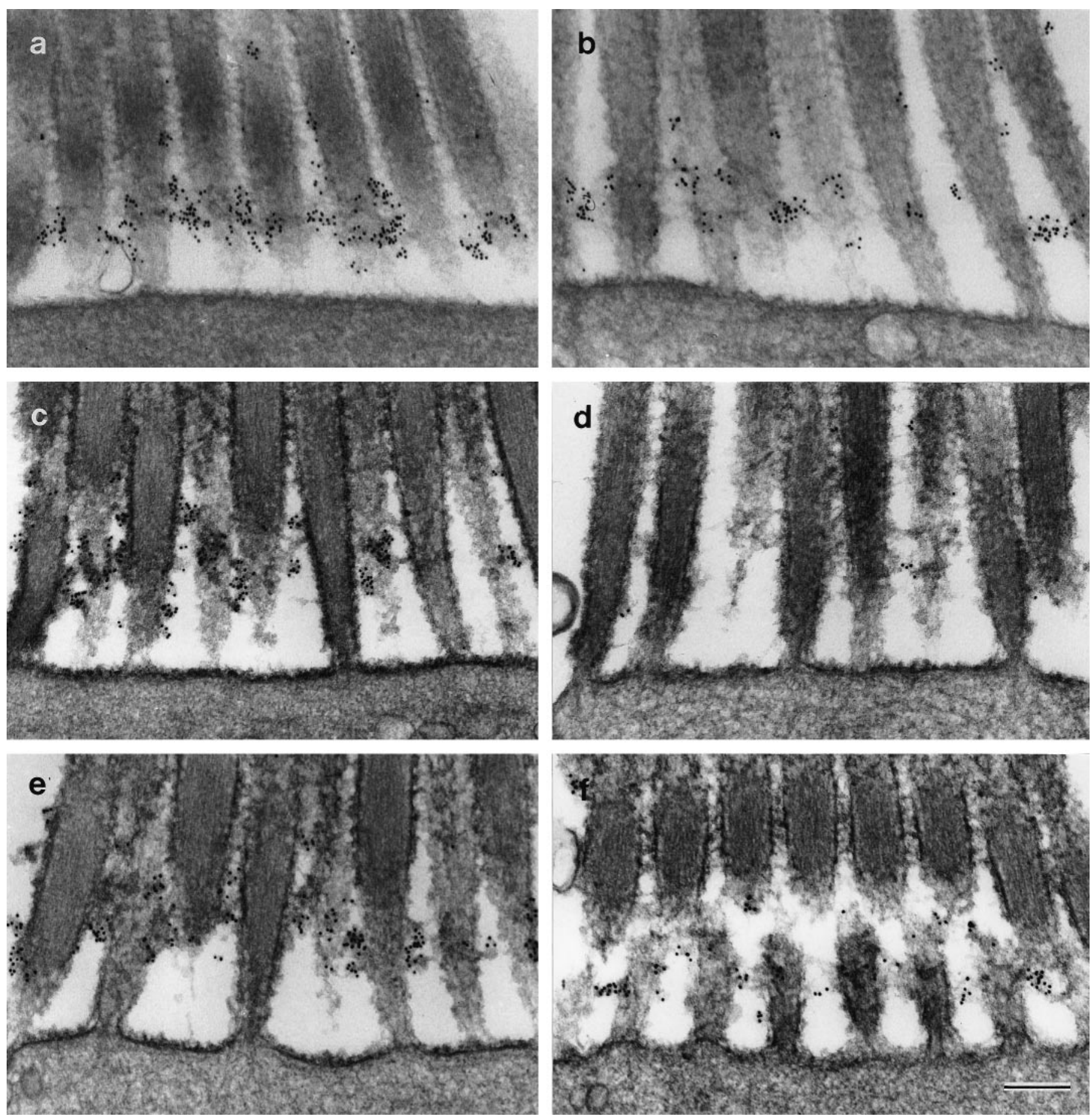

Figure 11. Ankle links and mAb E40 binding sites on extrastriolar hair cells from the utricular macula. $a, b$, Effects of BAPTA at $2^{\circ} \mathrm{C}$. Hair bundles from maculae incubated in HBHBSS $(a)$ or $5 \mathrm{~mm}$ BAPTA $(b)$ at $2^{\circ} \mathrm{C}$ for $20 \mathrm{~min}$. Ankle links and mAb E40 labeling are present but reduced after BAPTA treatment at $2^{\circ} \mathrm{C} . c-f$, In vitro recovery. Hair bundles from control $(c, e)$ and BAPTA-treated $(d, f)$ maculae fixed immediately before $(c, d)$ or $20 \mathrm{hr}$ after $(e, f)$ a $20 \mathrm{hr}$ period of in vitro culture. Both ankle links and mAb E40 labeling recover in vitro after BAPTA treatment $(f)$. Maculae were labeled with $\mathrm{mAb}$ E40, rabbit anti-mouse $\mathrm{IgG}_{1}$, and $10 \mathrm{~nm}$ gold-conjugated $\mathrm{IgG}$, and refixed in the presence of ruthenium red. Scale bar, $300 \mathrm{~nm}$.

developed in rodents and is often badly preserved in human tissue. In the chick, the ALA is associated with the calycal processes adjacent to the connecting cilium and is found both between the calycal processes and the connecting cilium as well as between the calycal processes themselves. The ALA could therefore be a component of both the connecting cilium membrane and the membrane of the calycal processes, and be part of a trans- membrane complex that interacts with myosin VIIA in both hair cells and photoreceptors. In hair cells, myosin VIIA is required for aminoglycoside accumulation, and it may either transport an aminoglycoside receptor to the cell surface, indirectly translocate such a receptor to sites of membrane retrieval, or retain such a receptor in the endocytotic pathway (Richardson et al., 1997). Although, the ALA could be a putative aminoglycoside receptor 
in the ear, there are likely to be other receptors in the eye because the retinal pigment epithelium, which is also enriched in myosin VIIA (Hasson et al., 1995; El-Amraoui et al., 1996), appears to be the principal site of aminoglycoside accumulation (Tabatabay et al., 1990). Nonetheless, the ALA is expressed by both hair cells and photoreceptors and localizes to regions where myosin VIIA is concentrated in both cell types, and could therefore be the product of a gene for one of the as yet unidentified Usher's syndrome genes, mutations of which lead to both deafness and blindness.

\section{REFERENCES}

Assad JA, Shepherd GMG, Corey DP (1991) Tip-link integrity and mechanical transduction in vertebrate hair cells. Neuron 7:987-994.

Crawford AC, Evans MG, Fettiplace R (1991) The actions of calcium on the mechanoelectrical transducer current of turtle hair cells. J Physiol (Lond) 434:369-398.

Csukas SR, Rosenquist TH, Mulroy MJ (1987) Connections between stereocilia in auditory hair cells of the alligator lizard. Hear Res 30:147-156.

El-Amraoui A, Sahly I, Picaud S, Sahel J, Abitol M, Petit C (1996) Human Usher 1B/mouse shaker-1; the retinal phenotype discrepancy explained by the presence/absence of myosin VIIA in the photoreceptor cells. Hum Mol Genet 5:1171-1178.

Fetter RD, Corless JM (1987) Morphological components associated with frog cone outer segment disc margins. Invest Ophthalmol Vis Sci 28:646-657.

Golz R, Thurm U (1992) Monoclonal antibodies against surface components of the mechano- and chemosensitive cnidocil complex of Hydra vulgaris. Cell Tissue Res 268:2327-2333.

Goodyear R, Richardson G (1992) Distribution of the $275 \mathrm{kD}$ hair cell antigen and cell surface specialisations on auditory and vestibular hair bundles in the chicken inner ear. J Comp Neurol 325:243-256.

Hasson T, Heintzelman MB, Santos-Sacchi J, Corey DP, Mooseker MS (1995) Expression in cochlea and retina of myosin VIIa, the gene product defective in Usher syndrome type 1B. Proc Natl Acad Sci USA 92:9815-9819.

Hasson T, Gillespie PG, Garcia JA, Macdonald RB, Zhao Y, Yee AG, Mooseker MS, Corey DP (1997) Unconventional myosin in inner-ear sensory epithelia. J Cell Biol 137:1287-1307.

Hirokawa N, Tilney LG (1982) Interactions between actin filaments and between actin filaments and membranes in quick-frozen and deeply etched hair cells of the chick ear. J Cell Biol 95:249-261.

Jacobs RA, Hudspeth AJ (1990) Ultrastructural correlates of mechanoelectrical transduction in hair cells of the bullfrog's internal ear. Cold Spring Harb Symp Quant Biol 55:547-561.

Kohler G, Milstein C (1975) Continuous culture of fused cells secreting antibody of predefined specificity. Nature 256:495-497.
Liu X, Vansant G, Udovinchenko IP, Wolfrum U, Williams DS (1997) Myosin VIIa, the product of the Usher $1 \mathrm{~b}$ syndrome gene, is concentrated in the connecting cilia of photoreceptor cells. Cell Motil Cytoskeleton 37:240-252.

Nagel G, Neugebauer D-Ch, Schmidt B, Thurm U (1991) Structures transmitting stimulatory force to the sensory hairs of vestibular ampullae of fishes and frogs. Cell Tissue Res 265:567-578.

Neugebauer D-Ch, Thurm U (1987) Surface charges of the membrane and cell adhesion substances determine the structural integrity of hair bundles from the inner ear of fish. Cell Tissue Res 249:199-207.

Pickles JO, Corey DP (1992) Mechanoelectrical transduction by hair cells. Trends Neurosci 15:254-259.

Pickles JO, Comis SD, Osborne (1984) Cross-links between stereocilia in the guinea pig organ of Corti and their possible relation to sensory transduction. Hear Res 15:103-112.

Pickles JO, Brix J, Comis SD, Gleich O, Köppl C, Manley GA, Osborne MP (1989) The organisation of tip links and stereocilia on hair cells of bird and lizard basilar papillae. Hear Res 41:31-42.

Pickles JO, von Perger M, Rouse GW, Brix J (1991) The development of links between stereocilia in hair cells of the chick basilar papilla. Hear Res 54:153-163.

Reynolds (1963) The use of lead citrate at high $\mathrm{pH}$ as an electron dense stain in electron microscopy. J Cell Biol 17:208-212.

Richardson GP, Bartolami S, Russell IJ (1990) Identification of a 275 $\mathrm{kDa}$ protein associated with the apical surfaces of sensory hair cells in the avian inner ear. J Cell Biol 110:1055-1066.

Richardson GP, Forge A, Kros CJ, Fleming J, Brown SDM, Steel KP (1997) Myosin VIIA is required for aminoglycoside uptake in cochlear hair cells. J Neurosci 17:9506-9519.

Sobkowicz HM, August BK, Slapnick SM (1992) Epithelial repair following mechanical injury of the developing organ of Corti in culture: an electron microscopic and autoradiographic study. Exp Neurol 115:44-49.

Tabatabay CA, Young LHY, D'Amico DJ, Kenyon KR (1990) Immunocytochemical localisation of gentamicin in the rabbit retina following intravitreal injection. Arch Ophthalmol 108:723-726.

Takeichi M (1990) Cadherins: a molecular family important in selective cell-cell adhesion. Annu Rev Biochem 59:237-252.

Watson GM, Mire P, Hudson RR (1998) Repair of hair bundles in sea anemones by secreted proteins. Hear Res 115:119-128.

Weil D, Blanchard S, Kaplan J, Guilford P, Gibson F, Walsh J, Mburu P, Varela A, Levilliers J, Weston MD, Kelley PM, Kimberling WJ, Wagenar M, Levi-Acobas F, Larget-Piet D, Munich A, Steel KP, Brown SDM, Petit C (1995) Defective myosin VIIA gene responsible for Usher syndrome type 1B. Nature 374:60-61.

Zhao Y, Yamoah EN, Gillespie PG (1996) Regeneration of broken tip links and restoration of mechanical transduction in hair cells. Proc Natl Acad Sci USA 94:15469-15474. 